Proceedings

\title{
Forecasting Low Stream Flow Rate Using Monte-Carlo Simulation of Perigiali Stream, Kavala City, NE Greece ${ }^{\dagger}$
}

\author{
Thomas Papalaskaris ${ }^{1, *}$ and Theologos Panagiotidis ${ }^{2}$ \\ 1 Department of Civil Engineering, Democritus University of Thrace, Kimmeria Campus, \\ 67100 Xanthi, Greece \\ 2 Department of Mechanical Engineering, Eastern Macedonia \& Thrace Institute of Technology, \\ 65404 Kavala, Greece; tpanag@teiemt.gr \\ * Correspondence: tpapalas@civil.duth.gr; Tel.: +30-6977-507545 \\ + Presented at the 3rd EWaS International Conference on "Insights on the Water-Energy-Food Nexus", \\ Lefkada Island, Greece, 27-30 June 2018.
}

Published: 20 August 2018

\begin{abstract}
A small number of scientific research studies with reference to extremely low flow conditions, have been conducted in Greece, so far. Predicting future low stream flow rate values is an essential and of paramount importance task when compiling watershed and drought management plans, designing water reservoirs and general hydraulic works capacity, calculating hydrological and drought low flow values, separating groundwater base flow and storm flow of storm hydrographs etc. The Monte-Carlo simulation method generates multiple attempts to define the anticipated value of a random (hydrological in this specific case) variable. The present study compiles, correspondingly, artificial low stream flow time series of both the same part of the year (2016) as well as a part of the calendar year (2017), based on the stream flow data observed during the same two different interval periods of the years 2016 and 2017, using a 3-inches U.S.G.S. modified portable Parshall flume, a 3-inches conventional portable Parshall flume, a 3-inches portable Montana (short Parshall) flume and a $90^{\circ} \mathrm{V}$-notched triangular shaped sharp crested portable weir plate. The recorded data were plotted against the fitted one and the results were demonstrated through interactive tables providing us the ability to effectively evaluate the simulation procedure performance. Finally, we plot the observed against the calculated low stream flow rate data, compiling a log-log scale chart which provides a better visualization of the discrepancy ratio statistical performance metric and calculate statistics featuring the comparison between the recorded and the forecasted low stream flow rate data.
\end{abstract}

Keywords: artificial time series; discrepancy ratio; Monte-Carlo simulation; low flow data; Parshall flume

\section{Introduction}

Low flow regimes in rivers and streams are of paramount importance to the ecological conditions of any land surface hydrological feature. Any shift in the flows pattern throughout any hydrological year, stemming, for instance, from either individual activities e.g., groundwater abstraction, precipitation shortage, riparian areas encroachment, stream channelizing due to urbanization etc, or a combination of them, may contribute to stream ecology changes that cannot be undone [1]. Low flow analysis and forecasting is also fundamental when building works along watercourses (e.g., dams, reservoirs, water deviation channels for irrigation purposes etc.) and for 
watercourse rehabilitation plans regarding which a knowledge of hydrological fluctuation is of fundamental importance in designing sustainable rehabilitation works.

Another type of low flow analysis, specifically probability distribution analysis, was performed in the past analyzing the observed data collected at the same gauging station between 14th of May 2016 and 31th of July 2016 revealing that Pearson type 6 (3P) demonstrated the highest final goodness of fit obtained score based, simultaneously, on all available (Anderson-Darling, Chi-Squared and Kolmogorov-Smirnov) goodness of fit criteria [2]. Furthermore, as far as the same gauging station, similar type of analysis was elaborated considering, this time, the observed data collected at the same gauging station both between 14th of May 2016 and 29th of August 2016 revealing that Wakeby type $(5 \mathrm{P})$ probability density function demonstrated the highest final goodness of fit obtained score based on the Kolmogorov-Smirnov goodness of fit criterion and employed to generate an artificial low flow time series for the same time interval [3,4]. Moreover, as far as another gauging station, more specifically the Palaia Kavala Stream gauging station, similar type of analysis was elaborated considering, this time, the 174 observed data collected between 17th of August 2013 and 7th of February 2014 revealing that Kumaraswamy type (4P) probability density function demonstrated the highest final goodness of fit obtained score based on the Kolmogorov-Smirnov goodness of fit criterion and employed to generate an artificial low flow time series for the same time interval [5].

The Monte-Carlo method is a class of computational algorithms that rely on repeated random sampling to compute their results [6]. "Monte Carlo" is synonymous to "stochastic"; In other words, the Monte Carlo method is a numerical method which, like other numerical methods, becomes useful when analytical solutions do not exist (that is, almost always...); While the Monte Carlo method seems to be a natural choice when the problem studied involves randomness, it is also powerful even for purely deterministc problems [7]. The Monte-Carlo simulations were additionally employed to model the high variability of each of the sewage base flows (SBF) components, implementing simultaneously a method of quantifying each of those components using residential end-use modeling [8]. Monte Carlo simulation models have also been used for riverine biological research purposes [9].

\section{Study Area}

The stream flow rate gauging station established in Kavala city coastal area, is located at the north of the Aegean Sea, across the Thassos Island, and surrounded by the Lekani mountain series branches to the North and East and the Paggaion Mountain ramifications to the West, (established in the proximity of the city urban web center and at the eastern exit of the city as well), located at the specific co-ordinates $40^{\circ} 56^{\prime} 727^{\prime \prime} \mathrm{N}$ and $24^{\circ} 25^{\prime} 929^{\prime \prime}$ E, Perigiali city area, and operated continuously, bridging a time interval period from 14 May 2016 to 7 October 2017, as illustrated in Figure 1.

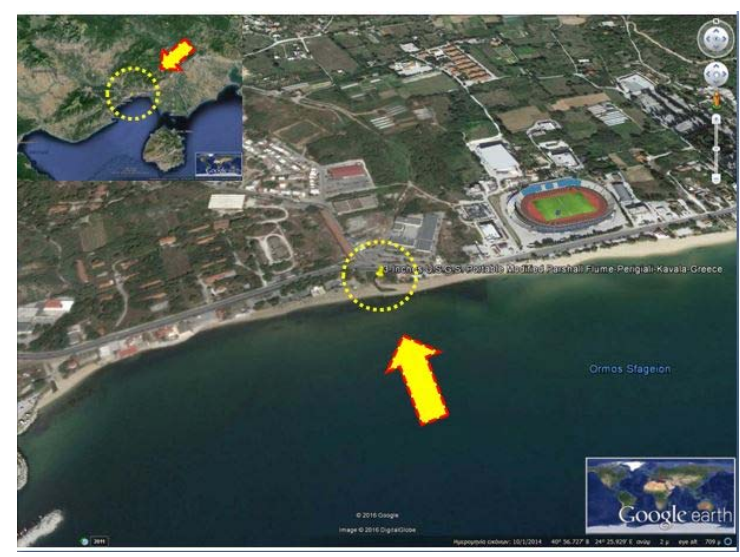

Figure 1. Parshall flumes and V-Notched weir gauging station, Perigiali Stream area, Kavala city, Greece. 
It should be noted that since it is located just a few decades of meters upstream the sea shore and simultaneously at the exit of the entire Perigiali area watershed, between the sea shore and the Old National Road connecting the eastern exit of the Kavala city to the Xanthi city, drained by the homonymous Perigiali area stream, the associated stream flow rate measurements provide profaoundly valuable scientific information respecting the entire regime of the water resources of the Perigiali area watershed.

The particular characteristics of the gauging station, namely, outlet of the entire watershed, outlet of the watershed's main stream channel, in close proximity to the seashore, North-Eastern Mediterranean location, partly urbanized watershed makes it of paramount importance since the observed (especially low flow) hydrological regimes could enhance drought, watershed and urban water management plans which could be used for the scientific research study of ungauged catchments with similar to the Perigiali Stream watershed spatial characteristics established within areas dominated by meteorological parameters of the same nature, magnitude and general characteristics.

\section{Materials and Methods}

We implemented the Monte-Carlo simulation method to simulate low stream flow rate data, acquired at a certain location of the partly channelized semi-urban stream which crosses the eastern exit of Kavala city, Eastern Macedonia \& Thrace Prefecture, NE Greece, during part of May, June, July and part of August 2016 until the 29th of August 2016, as well as part of May, June, July, August, September and part of October 2017, until the 10th of October 2017, (see Supplementary).

The distinctively shallow waters, exacerbated by the extremely low water stream flow velocity occurring at the gauging station, make impossible to perform the area-velocity method in order to calculate the stream flow rate (discharge), using a current meter mounted on a wading rod, due to the fact that there isn't adequate depth to submerge the current meter; Moreover, the pronounced low water stream flow velocity is not sufficient enough to trigger the operation of a current meter. Under those noticeable circumstances the only other remaining options, are the use of either a small-sized portable weir (all those its implementation brings difficulties due to the fact that weirs, in general, demand a relatively great head loss which is not available at areas in proximity to watersheds' outlets, where, in most cases, the natural slope of the channel bed is extremely low if not zero) plate or/and a small-sized flume or/and a set of small-sized weir and flumes which, eventually, was our final selected option, more specifically, a "3-inch U.S.G.S. Modified Portable Parshall Flume", "3-inch U.S.G.S. Conventional Portable Parshall Flume" and a "90 V-Notched Triangular-Shaped Sharp-Crested (Sharp-Edged) U.S.G.S. Portable Weir Plate" [10-20], made of sea plywood, covered with a sprayed thin smooth polyester coating, (identical to that usually the industry covers the outside surface of high-speed sea boats, in order to reduce the friction developing between the outside area of those sea boats and the sea water, thus securing that the friction developed between the bottom as well as the walls of the stream flow rate gauging apparatus is minimized/restricted to a minimum, as illustrated in Figure 2.

Meteorological data, namely, total daily rainfall $(\mathrm{mm})$, cumulative [1 January 2006-(14 May 2016-30 August 2016)] and [1 January 2006-(24 May 2017-7 October 2017)] total daily rainfall (mm), mean daily wind velocity $(\mathrm{km} / \mathrm{h})$, maximum daily wind velocity $(\mathrm{km} / \mathrm{h})$, mean daily temperature $\left({ }^{\circ} \mathrm{C}\right)$, minimum daily temperature $\left({ }^{\circ} \mathrm{C}\right)$, maximum daily temperature $\left({ }^{\circ} \mathrm{C}\right)$, mean daily air humidity $(\%)$, minimum daily air humidity $(\%)$, maximum daily air humidity $(\%)$, mean daily air pressure $(\mathrm{hPa})$, minimum daily air pressure $(\mathrm{hPa})$ and maximum daily air pressure $(\mathrm{hPa})$, has been collected from Dexameni-Kavala city-Eastern Macedonia \& Thrace Prefecture-Greece private meteorological station (located at 40 $56^{\prime} 25^{\prime \prime} \mathrm{N}-\mathrm{E} 24^{\circ} 24^{\prime} 01^{\prime \prime} \mathrm{E}$, Altitude:90 m).

The daily low stream flow rate (provided within Table A1) and the total daily rainfall for the two different time intervals (14 May 2016-30 August 2016 and 24 May 2017-7 October 2017) representing the two different time periods the Perigiali Stream, (Kavala city, Eastern Macedonia and Thrace Prefecture, North-Eeastern Greece) gauging station operated are depicted in contrast within the charts illustrated within the following Figure 3. 
Low stream flow rate values were forecasted employing the Monte-Carlo method that is an appropriate type of iteration method both for meteorological as well as for river stream flow rate predictions. The fundamental procedure of the Monte Carlo method generates a certain number of trials in order to specify the anticipated value of a random variable.

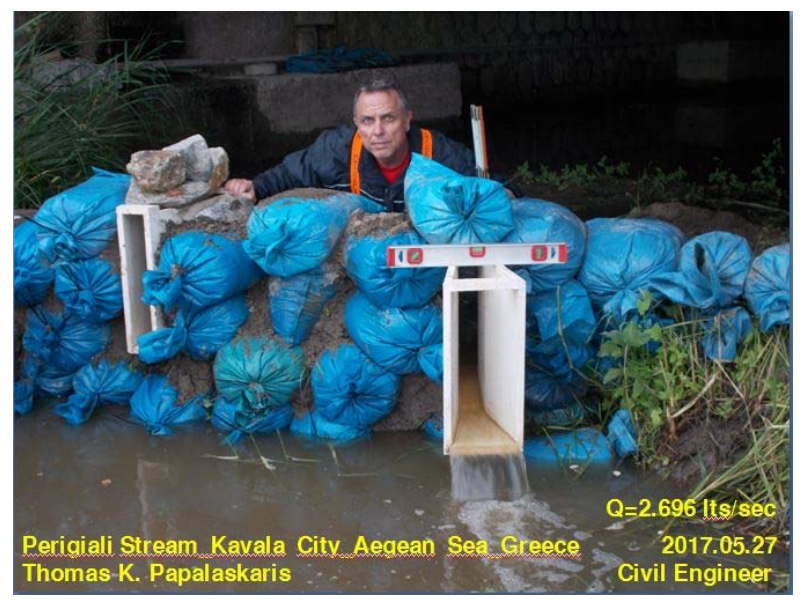

Figure 2. Parshall flumes and V-Notched weir gauging station, Perigiali Stream area, Kavala city, Greece, (see Supplementary Materials).

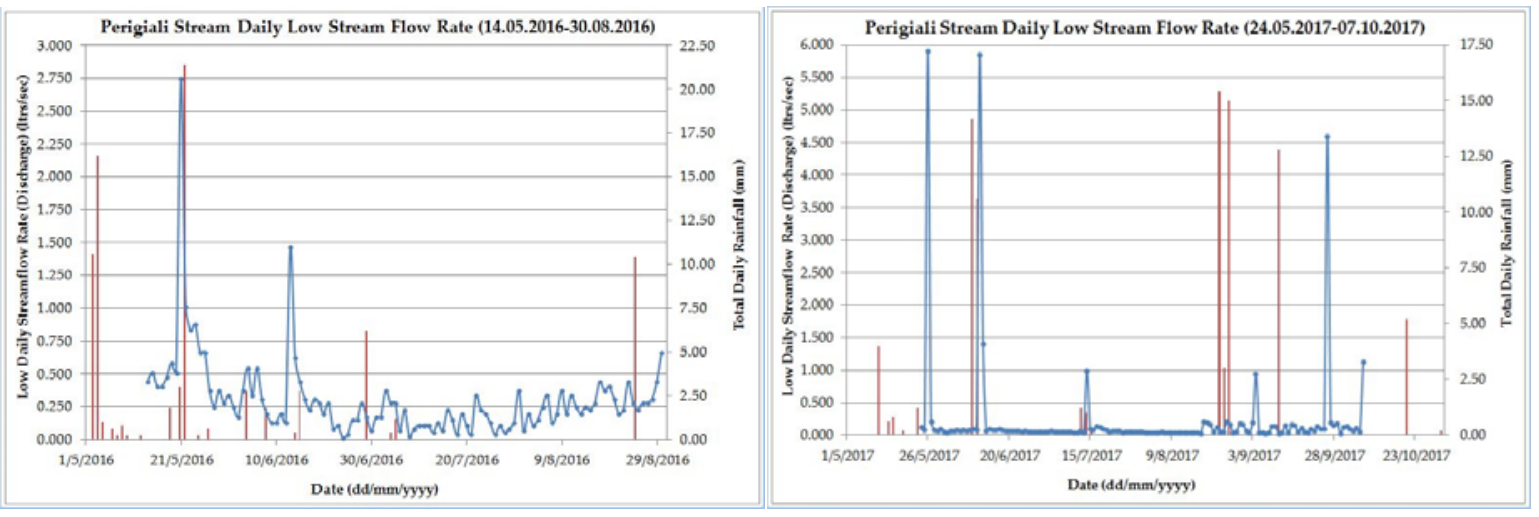

Figure 3. Parshall flumes and V-Notched weir gauging station, Perigiali Stream area, Kavala city, Greece [Daily low stream flow rate (continuous horizontal fluctuating blue line vs. Total daily rainfall (continuous vertical red bars), (14 May 2016-30 August 2016, on the left), (24 May 2017-7 October 2017, on the right)].

The presence of the 13 independent meteorological variables (predictors) involved implies a multivariate case, hence we constructed a linear equation containing all those variables, seeking a model relating those independent variables (predictors) and the daily low stream flow rate (dependent variable); More specifically, we followed the multiple regression procedure estimating a linear equation of linear form, (where " $Y$ " represents the), as depicted within Equation (1):

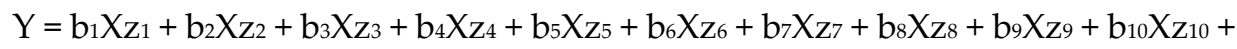

$$
\begin{aligned}
& b_{11} X_{Z 11}+b_{12} X_{Z 12}+b_{13} X_{Z 13}
\end{aligned}
$$

It should be noted that, although each of these independent variables can have a unique distribution we assumed, by the beginning, that all of them follow a uniform distribution, an assumption which doesn't violates the results and this conclusion is derived by examining the related statistical criteria (mean, median, skewness, kurtosis etc.), as depicted within the following Table 1. 
Table 1. Statistical criteria of Monte Carlo simulation for Perigiali Stream, Kavala city, Greece.

\begin{tabular}{ccccccc}
\hline $\begin{array}{c}\text { Number of } \\
\text { Iterations }\end{array}$ & $\begin{array}{c}\text { Expected Daily Low } \\
\text { Stream Flow Rate (Mean) }\end{array}$ & Median & $\begin{array}{c}\text { Standard } \\
\text { Deviation }\end{array}$ & $\begin{array}{c}\text { True (Reviewed) } \\
\text { Error of the Estimate }\end{array}$ & Kurtosis & Skewness \\
\hline 2138 & 2.596 & 2.614 & 1.858 & $0.121(4.644 \%)$ & -0.383 & 0.017 \\
\hline
\end{tabular}

Furthermore, we considered that each variable is independent of the others, meaning that each variable's value is not affected by the value of any other independent variable.

The corresponding coefficients $b_{1}, \ldots, b_{13}$, involved within Equation (1), were computed employing "MS Excel Solver" ("add-in") tool, in a way that minimizing the squared deviation (squared residuals) between observed and simulated daily low stream flow rate values was considered as a constraint. The positive values resulted from the procedure were collected afterwards in order to continue the procedure and we found the minimum and maximum simulated values, namely, $(0.001,4.784)$.

Then we implemented the model derived from Equation (1) employing the same computed coefficients values as well as the minimum and maximum values of all the independent variables resulting, correspondingly, to the calculation of the respective minimum and maximum values of the dependent variable " $Y$ " (daily low stream flow rate) values, namely, $(1.583,3.503)$ which lie between the interval margins defined by the previously referred corresponding values, namely, $(0.001,4.784)$. The procedure followed implies that any value of these independent variables employed herewith lie within a certain (respective to the nature of each one) interval.

Although several commercial packages running Monte Carlo Simulation are available, however a conventional "MS Excel" spreadsheet was employed to perform the simulation. In the present study, the multiple trials generation is enhanced by establishing a certain basic formula as many times as the number of iterations determined by the specified model.

Following this procedure, the daily low stream flow rate is a random dependent variable with a value which lies within the interval determined by the anticipated minimum and maximum daily low stream flow rate values. As an outcome, this dependent variable will be normally distributed since it represents the outcome of summing a number of certain random independent variables. This result justifies the reason that the specific distribution followed by each independent variable is not considered of a paramount importance.

The general architecture of the Monte Carlo method can be described as following:

- Generating random values for each of the independent (meteorological) variables involved

- Introduce each different series of random values involved to arrive at a total daily low stream flow rate value (dependent variable " $Y$ ")

- The anticipated daily low stream flow rate value is then considered the average resulted from these values.

\section{Results}

Below, a number of parameters that can be computed to conclude respecting the goodness of the derived simulating solution is illustrated and discussed. More specifically, the number of iterations required by the model, the expected daily low stream flow rate (mean, average) and the rest of statistical criteria (median, standard deviation, true error of the estimate, kurtosis and skewness) are depicted within the following Table 1.

The median arithmetic value is very close to the mean corresponding one (with a difference of only $0.69 \%$ ) implying that the dependent variable " $Y$ " (daily low stream flow rate) follows the normal distribution. The standard deviation was computed taking into consideration the entire range of the 2138 values of the population and is regarded as a fairly low one in value. The kurto-sis statistic metric value which is considered a relative measure of the shape (of the finally achieved distribution) compared with the shape of the normal distribution (which has a kurtosis value of 0 ) informs us that the finally achieved distribution (of the independent variable " $Y$ ") is somewhat flatter than a normal distribution. Furthermore, skewness arithmetic value provides us information with reference to how symmetric is the finally achieved distribution while compared with a normal 
distribution which has a skewness arithmetic value of 0 . In this study, the skewness arithmetic value of 0.017 suggests that the tail of the finally achieved distribution of the dependent variable extends somewhat towards the right.

Furthermore, after having simulated all the observed daily low stream flow rate values, the discrepancy ratio could be computed as an additional statistical performance metric [21].

\section{Discussion and Conclusions}

The Monte Carlo simulation method was employed and implemented to model the observed daily low stream low rate values of Perigiali Stream, Kavala city, Eastern Macedonia and Thrace Prefecture, North-Eastern Greece. Firstly, a multiple regression linear model was designed by investigating the relationships existing between the independent meteorological variables and the dependent one " $Y$ " (daily low stream flow rate values) and the corresponding coefficients $\left(b_{1}, b_{2} \ldots\right.$, $\left.b_{12}, b_{13}\right)$ of the independent variables were computed and produced the minimum and maximum marginal interval limits of the simulated daily low stream flow rate values range. Then, the "MS Excel Solver" ("add-in") tool was employed, in a way to minimize, as a constraint, the squared deviation (squared residuals) between observed and simulated daily low stream flow rate values. A conventional "MS Excel" spreadsheet was employed to establish and run the determined simulation, generating multiple trials by establishing a basic formula 2138 iterations times as required by the established model. Then, by assuming that each variable follows a uniform distribution we employed the "MS Excel" "RAND ()" function generating random numbers lying within the interval $(0,1)$ and multiplied these by the values of the entire range of all the independent meteorological variables. This range of values is actually determined by the difference between the corresponding maximum and minimum values. Then, we determined the number of iterations required by the model and computed the anticipated value of the daily low stream flow rate and also predicted the estimation error, which is proportional to the number of iterations. The computed statistical performance metrics indicates that by assuming from the beginning that the dependent variable (daily low stream flow rate values) " $Y$ " follows a normal distribution did not compromise the results.

The expected daily low stream flow rate value $(2.596 \mathrm{~L} / \mathrm{s})$ is considered rather fairly high, when compared with the most of the observed ones, suggesting that the observed low stream flow rate values might should be clustered in different arithmetic classes in accordance with their magnitude and manipulated independently by implementing the Monte Carlo procedure to each different class yielding simulated values of different magnitudes correspondingly to each class.

\section{Further Research}

Additionally, other architectural types of models, such as Artificial Neural Networks (ANN) schemes should be designed in order to further investigate the relationships between the independent meteorological variables and the dependent variable (daily low stream flow rate value) " $Y$ ", simulating daily low stream flow rate values of the maximum possible highest accuracy, enhancing watershed and drought management plans, water reservoirs designing, water deviation works for agricultural purposes, urban water management etc. [21].

Thus, the future extension of Perigiali Stream gauging station hydrological observations is considered, together with the collection of Dexameni private meteorogical station meteorological parameters, of paramount importance in order to further improve the various types of models which have been derived so far, (such as stochastic generation of artificial daily low stream flow rate data, design of artificial neural networks etc.), particularly, as far as the present study, the Monte Carlo simulation model.

Finally, the installation of additional gauging stations throughout the upstream area of the Perigiali watershed, by monitoring the stream flow rate regimes of the watershed's headwaters and low order streams, would contribute significantly to the broader understanding of the Perigiali catchment response, introducing additional parameters to the hydrological investigation thus further the derived hydrological models development. 
Supplementary Materials: The following are available online at https://www.youtube.com/watch? v=Wu8KBj3qqXg, Video S1: Watershed Stream Flow Measurement-Stream Perigiali-2016.06.18-Kavala City-Greece, https:/www.youtube.com/watch?v=-HbPZLNGplY\&feature=youtu.be, Video S2: Watershed Stream Flow Measurement-Stream Perigiali-2017.07.27(a)－Kavala City－Greece (08:16:49 a.m.).

Author Contributions: T.P. (Thomas Papalaskaris) performed the experiments; T.P. (Thomas Papalaskaris) and T.P. (Theologos Panagiotidis) analyzed the data; T.P. (Thomas Papalaskaris) and T.P. (Theologos Panagiotidis) contributed reagents/materials/analysis tools; T.P. (Thomas Papalaskaris) wrote the paper.

Conflicts of Interest: The authors declare no conflict of interest.

\section{Appendix A}

The dates of all measurements as well as both the site measured as well as the calculated stream flow rates of Perigiali Stream are presented in Table A1.

Table A1. Stream flow rate measurements of Perigiali Stream.

\begin{tabular}{|c|c|c|}
\hline No. & Date & $\begin{array}{c}\text { Stream Flow Rate }\left(\mathrm{m}^{3} / \mathrm{s}\right) \\
\text { Site-Measured }\end{array}$ \\
\hline 1 & $14-5-2016$ & 0.4370 \\
\hline 2 & $15-5-2016$ & 0.5080 \\
\hline 3 & $16-5-2016$ & 0.4030 \\
\hline 4 & $17-5-2016$ & 0.4030 \\
\hline 5 & $18-5-2016$ & 0.4720 \\
\hline 6 & $19-5-2016$ & 0.5830 \\
\hline 7 & $20-5-2016$ & 0.5080 \\
\hline 8 & $21-5-2016$ & 2.7460 \\
\hline 9 & $22-5-2016$ & 1.0110 \\
\hline 10 & $23-5-2016$ & 0.8300 \\
\hline 11 & $24-5-2016$ & 0.8740 \\
\hline 12 & $25-5-2016$ & 0.6620 \\
\hline 13 & $26-5-2016$ & 0.6620 \\
\hline 14 & 27-5-2016 & 0.3700 \\
\hline 15 & $28-5-2016$ & 0.2488 \\
\hline 16 & $29-5-2016$ & 0.3701 \\
\hline 17 & $30-5-2016$ & 0.2775 \\
\hline 18 & $31-5-2016$ & 0.3381 \\
\hline 19 & $1-6-2016$ & 0.2488 \\
\hline 20 & $2-6-2016$ & 0.1700 \\
\hline 21 & $3-6-2016$ & 0.3701 \\
\hline 22 & $4-6-2016$ & 0.5451 \\
\hline 23 & 5-6-2016 & 0.3381 \\
\hline 24 & $6-6-2016$ & 0.5450 \\
\hline 25 & $7-6-2016$ & 0.3072 \\
\hline 26 & $8-6-2016$ & 0.1950 \\
\hline 27 & $9-6-2016$ & 0.1238 \\
\hline 28 & $10-6-2016$ & 0.1238 \\
\hline 29 & $11-6-2016$ & 0.1950 \\
\hline 30 & $12-6-2016$ & 0.1238 \\
\hline 31 & 13-6-2016 & 1.4650 \\
\hline 32 & 14-6-2016 & 0.6220 \\
\hline 33 & 15-6-2016 & 0.4371 \\
\hline 34 & 16-6-2016 & 0.3072 \\
\hline 35 & $17-6-2016$ & 0.2213 \\
\hline
\end{tabular}




\begin{tabular}{|c|c|c|}
\hline 36 & $18-6-2016$ & 0.3072 \\
\hline 37 & $19-6-2016$ & 0.2775 \\
\hline 38 & $20-6-2016$ & 0.1950 \\
\hline 39 & 21-6-2016 & 0.2775 \\
\hline 40 & $22-6-2016$ & 0.0832 \\
\hline 41 & 23-6-2016 & 0.1028 \\
\hline 42 & $24-6-2016$ & 0.0115 \\
\hline 43 & $25-6-2016$ & 0.0344 \\
\hline 44 & $26-6-2016$ & 0.1462 \\
\hline 45 & 27-6-2016 & 0.1462 \\
\hline 46 & 28-6-2016 & 0.2775 \\
\hline 47 & 29-6-2016 & 0.1700 \\
\hline 48 & $30-6-2016$ & 0.0652 \\
\hline 49 & 1-7-2016 & 0.1700 \\
\hline 50 & $2-7-2016$ & 0.1700 \\
\hline 51 & $3-7-2016$ & 0.3701 \\
\hline 52 & $4-7-2016$ & 0.2775 \\
\hline 53 & $5-7-2016$ & 0.2775 \\
\hline 54 & $6-7-2016$ & 0.0652 \\
\hline 55 & $7-7-2016$ & 0.2213 \\
\hline 56 & 8-7-2016 & 0.0218 \\
\hline 57 & $9-7-2016$ & 0.0832 \\
\hline 58 & $10-7-2016$ & 0.1028 \\
\hline 59 & $11-7-2016$ & 0.1028 \\
\hline 60 & $12-7-2016$ & 0.1028 \\
\hline 61 & 13-7-2016 & 0.0489 \\
\hline 62 & $14-7-2016$ & 0.1238 \\
\hline 63 & $15-7-2016$ & 0.0652 \\
\hline 64 & $16-7-2016$ & 0.2213 \\
\hline 65 & $17-7-2016$ & 0.1462 \\
\hline 66 & $18-7-2016$ & 0.0344 \\
\hline 67 & $19-7-2016$ & 0.1950 \\
\hline 68 & $20-7-2016$ & 0.1028 \\
\hline 69 & $21-7-2016$ & 0.0344 \\
\hline 70 & $22-7-2016$ & 0.3381 \\
\hline 71 & $23-7-2016$ & 0.2213 \\
\hline 72 & $24-7-2016$ & 0.1950 \\
\hline 73 & $25-7-2016$ & 0.1238 \\
\hline 74 & $26-7-2016$ & 0.0340 \\
\hline 75 & 27-7-2016 & 0.1028 \\
\hline 76 & $28-7-2016$ & 0.0489 \\
\hline 77 & $29-7-2016$ & 0.0832 \\
\hline 78 & $30-7-2016$ & 0.1238 \\
\hline 79 & $31-7-2016$ & 0.3701 \\
\hline 80 & 1-8-2016 & 0.0652 \\
\hline 81 & $2-8-2016$ & 0.1950 \\
\hline 82 & $3-8-2016$ & 0.1028 \\
\hline 83 & $4-8-2016$ & 0.1462 \\
\hline 84 & 5-8-2016 & 0.2488 \\
\hline 85 & $6-8-2016$ & 0.3381 \\
\hline 86 & 7-8-2016 & 0.1238 \\
\hline 87 & $8-8-2016$ & 0.1950 \\
\hline
\end{tabular}




\begin{tabular}{|c|c|c|}
\hline 88 & $9-8-2016$ & 0.3701 \\
\hline 89 & $10-8-2016$ & 0.1950 \\
\hline 90 & $11-8-2016$ & 0.3381 \\
\hline 91 & $12-8-2016$ & 0.2488 \\
\hline 92 & $13-8-2016$ & 0.1950 \\
\hline 93 & $14-8-2016$ & 0.2488 \\
\hline 94 & $15-8-2016$ & 0.2219 \\
\hline 95 & $16-8-2016$ & 0.2775 \\
\hline 96 & $17-8-2016$ & 0.4371 \\
\hline 97 & $18-8-2016$ & 0.3701 \\
\hline 98 & $19-8-2016$ & 0.4031 \\
\hline 99 & $20-8-2016$ & 0.3072 \\
\hline 100 & $21-8-2016$ & 0.1950 \\
\hline 101 & $22-8-2016$ & 0.2213 \\
\hline 102 & $23-8-2016$ & 0.4371 \\
\hline 103 & $24-8-2016$ & 0.2775 \\
\hline 104 & $25-8-2016$ & 0.2213 \\
\hline 105 & $26-8-2016$ & 0.2775 \\
\hline 106 & 27-8-2016 & 0.2775 \\
\hline 107 & $28-8-2016$ & 0.3072 \\
\hline 108 & 29-8-2016 & 0.4371 \\
\hline 109 & $30-8-2016$ & 0.6616 \\
\hline 110 & $24-5-2017$ & 0.1210 \\
\hline 111 & $25-5-2017$ & 0.0820 \\
\hline 112 & $26-5-2017$ & 5.9150 \\
\hline 113 & $27-5-2017$ & 0.2130 \\
\hline 114 & $28-5-2017$ & 0.0820 \\
\hline 115 & 29-5-2017 & 0.0650 \\
\hline 116 & $30-5-2017$ & 0.1010 \\
\hline 117 & $31-5-2017$ & 0.0490 \\
\hline 118 & $1-6-2017$ & 0.0340 \\
\hline 119 & 2-6-2017 & 0.0650 \\
\hline 120 & $3-6-2017$ & 0.0650 \\
\hline 121 & 4-6-2017 & 0.0820 \\
\hline 122 & 5-6-2017 & 0.0650 \\
\hline 123 & $6-6-2017$ & 0.0820 \\
\hline 124 & 7-6-2017 & 0.0650 \\
\hline 125 & 8-6-2017 & 0.0820 \\
\hline 126 & $9-6-2017$ & 0.1010 \\
\hline 127 & $10-6-2017$ & 0.0820 \\
\hline 128 & $11-6-2017$ & 5.8560 \\
\hline 129 & $12-6-2017$ & 1.4010 \\
\hline 130 & $13-6-2017$ & 0.0650 \\
\hline 131 & $14-6-2017$ & 0.1010 \\
\hline 132 & $15-6-2017$ & 0.0820 \\
\hline 133 & $16-6-2017$ & 0.0820 \\
\hline 134 & $17-6-2017$ & 0.1010 \\
\hline 135 & $18-6-2017$ & 0.0820 \\
\hline 136 & $19-6-2017$ & 0.0650 \\
\hline 137 & 20-6-2017 & 0.0650 \\
\hline 138 & 21-6-2017 & 0.0650 \\
\hline 139 & $22-6-2017$ & 0.0650 \\
\hline
\end{tabular}




\begin{tabular}{|c|c|c|}
\hline 140 & 23-6-2017 & 0.0650 \\
\hline 141 & 24-6-2017 & 0.0490 \\
\hline 142 & $25-6-2017$ & 0.0650 \\
\hline 143 & 26-6-2017 & 0.0490 \\
\hline 144 & 27-6-2017 & 0.0490 \\
\hline 145 & 28-6-2017 & 0.0490 \\
\hline 146 & 29-6-2017 & 0.0490 \\
\hline 147 & 30-6-2017 & 0.0490 \\
\hline 148 & 1-7-2017 & 0.0490 \\
\hline 149 & 2-7-2017 & 0.0490 \\
\hline 150 & $3-7-2017$ & 0.0645 \\
\hline 151 & 4-7-2017 & 0.0486 \\
\hline 152 & $5-7-2017$ & 0.0486 \\
\hline 153 & 6-7-2017 & 0.0486 \\
\hline 154 & $7-7-2017$ & 0.0486 \\
\hline 155 & $8-7-2017$ & 0.0486 \\
\hline 156 & $9-7-2017$ & 0.0486 \\
\hline 157 & $10-7-2017$ & 0.0344 \\
\hline 158 & $11-7-2017$ & 0.0344 \\
\hline 159 & 12-7-2017 & 0.0645 \\
\hline 160 & $13-7-2017$ & 0.0344 \\
\hline 161 & $14-7-2017$ & 0.9872 \\
\hline 162 & $15-7-2017$ & 0.1007 \\
\hline 163 & $16-7-2017$ & 0.0819 \\
\hline 164 & $17-7-2017$ & 0.1421 \\
\hline 165 & $18-7-2017$ & 0.1208 \\
\hline 166 & 19-7-2017 & 0.1007 \\
\hline 167 & $20-7-2017$ & 0.0819 \\
\hline 168 & $21-7-2017$ & 0.0486 \\
\hline 169 & $22-7-2017$ & 0.0645 \\
\hline 170 & 23-7-2017 & 0.0645 \\
\hline 171 & $24-7-2017$ & 0.0645 \\
\hline 172 & $25-7-2017$ & 0.0344 \\
\hline 173 & $26-7-2017$ & 0.0486 \\
\hline 174 & 27-7-2017 & 0.0486 \\
\hline 175 & 28-7-2017 & 0.0486 \\
\hline 176 & 29-7-2017 & 0.0486 \\
\hline 177 & $30-7-2017$ & 0.0486 \\
\hline 178 & $31-7-2017$ & 0.0486 \\
\hline 179 & 1-8-2017 & 0.0344 \\
\hline 180 & 2-8-2017 & 0.0344 \\
\hline 181 & 3-8-2017 & 0.0344 \\
\hline 182 & $4-8-2017$ & 0.0344 \\
\hline 183 & $5-8-2017$ & 0.0344 \\
\hline 184 & 6-8-2017 & 0.0486 \\
\hline 185 & $7-8-2017$ & 0.0344 \\
\hline 186 & 8-8-2017 & 0.0344 \\
\hline 187 & $9-8-2017$ & 0.0344 \\
\hline 188 & $10-8-2017$ & 0.0344 \\
\hline 189 & 11-8-2017 & 0.0344 \\
\hline 190 & $12-8-2017$ & 0.0344 \\
\hline 191 & 13-8-2017 & 0.0344 \\
\hline
\end{tabular}




\begin{tabular}{|c|c|c|}
\hline 192 & 14-8-2017 & 0.0344 \\
\hline 193 & $15-8-2017$ & 0.0344 \\
\hline 194 & $16-8-2017$ & 0.0344 \\
\hline 195 & $17-8-2017$ & 0.0344 \\
\hline 196 & 18-8-2017 & 0.0221 \\
\hline 197 & $19-8-2017$ & 0.2060 \\
\hline 198 & $20-8-2017$ & 0.1890 \\
\hline 199 & 21-8-2017 & 0.1670 \\
\hline 200 & $22-8-2017$ & 0.0486 \\
\hline 201 & 23-8-2017 & 0.1210 \\
\hline 202 & 24-8-2017 & 0.0486 \\
\hline 203 & $25-8-2017$ & 0.0486 \\
\hline 204 & 26-8-2017 & 0.2070 \\
\hline 205 & $27-8-2017$ & 0.1690 \\
\hline 206 & 28-8-2017 & 0.0344 \\
\hline 207 & 29-8-2017 & 0.0486 \\
\hline 208 & $30-8-2017$ & 0.1770 \\
\hline 209 & $31-8-2017$ & 0.1710 \\
\hline 210 & 1-9-2017 & 0.0730 \\
\hline 211 & 2-9-2017 & 0.0470 \\
\hline 212 & 3-9-2017 & 0.1930 \\
\hline 213 & $4-9-2017$ & 0.9439 \\
\hline 214 & $5-9-2017$ & 0.0344 \\
\hline 215 & 6-9-2017 & 0.0360 \\
\hline 216 & 7-9-2017 & 0.0320 \\
\hline 217 & 8-9-2017 & 0.0430 \\
\hline 218 & 9-9-2017 & 0.1390 \\
\hline 219 & 10-9-2017 & 0.1370 \\
\hline 220 & $11-9-2017$ & 0.0220 \\
\hline 221 & $12-9-2017$ & 0.0344 \\
\hline 222 & $13-9-2017$ & 0.1450 \\
\hline 223 & 14-9-2017 & 0.0344 \\
\hline 224 & $15-9-2017$ & 0.1610 \\
\hline 225 & $16-9-2017$ & 0.1490 \\
\hline 226 & $17-9-2017$ & 0.0486 \\
\hline 227 & 18-9-2017 & 0.1080 \\
\hline 228 & 19-9-2017 & 0.0486 \\
\hline 229 & $20-9-2017$ & 0.0344 \\
\hline 230 & 21-9-2017 & 0.0990 \\
\hline 231 & 22-9-2017 & 0.0714 \\
\hline 232 & 23-9-2017 & 0.1380 \\
\hline 233 & 24-9-2017 & 0.0996 \\
\hline 234 & $25-9-2017$ & 0.0934 \\
\hline 235 & $26-9-2017$ & 4.6003 \\
\hline 236 & 27-9-2017 & 0.1870 \\
\hline 237 & 28-9-2017 & 0.1510 \\
\hline 238 & 29-9-2017 & 0.1790 \\
\hline 239 & $30-9-2017$ & 0.0330 \\
\hline 240 & $1-10-2017$ & 0.1280 \\
\hline 241 & $2-10-2017$ & 0.1420 \\
\hline 242 & 3-10-2017 & 0.0910 \\
\hline 243 & $4-10-2017$ & 0.0650 \\
\hline
\end{tabular}




\begin{tabular}{lll}
244 & $5-10-2017$ & 0.1050 \\
245 & $6-10-2017$ & 0.0590 \\
246 & $7-10-2017$ & 1.1245 \\
\hline
\end{tabular}

\section{References}

1. Gustard, A.; Demuth, S. Estimating, Predicting and Forecasting Low Flows. In Manual on Low-Flow Estimation and Prediction (Operational Hydrology Report No. 50), 1st ed.; Gustard, A., Demuth, S., Eds.; World Meteorological Organization (WMO): Geneva, Switzerland, 2008; Volume 1029, pp. 16-21.

2. Papalaskaris, T.; Panagiotidis, T. Artificial Low Stream Flow Time Series Generation of Perigiali Stream, Kavala city, NE Greece. In Proceedings of the 6th International Symposium on Environmental \& Material Flow Management (6th E.M.F.M.), Bor, Serbia, 2-4 October 2016; dr Živan, Ž., dr Ivan, M., dr Predrag, D., Eds.; University of Belgrade, Technical Faculty in Bor: Bor, Serbia, 2016; pp. 20-38.

3. Papalaskaris, T.; Panagiotidis, T. Stochastic generation of low stream flow data of Perigiali Stream, Kavala city, NE Greece. In Proceedings of the 10th World Congress of European Water Resources Association (“E.W.R.A.") on Water Resources and Environment "Panta Rhei” 2017 (10th “E.W.R.A." "Panta Rhei” 2017), Athens, Greece, 5-9 July 2017; George, T., Vassilios, T., Harris, V., Dimitris, T., Eds.; European Water Resources Association (E.W.R.A.): Athens, Greece, 2017; pp. 953-960.

4. Papalaskaris, T.; Panagiotidis, T. Stochastic generation of low stream flow data of Perigiali Stream, Kavala city, NE Greece. Eur. Water 2017, 60, 299-306. doi:10.1623/hysj.51.4.563. Available online: http://ewra.net/ew/pdf/EW_2017_60_41.pdf (accessed on 3 March 2018).

5. Papalaskaris, T.; Panagiotidis, T. Artificial low stream flow time series generation of Palaia Kavala Stream, Kavala City, NE Greece. In Proceedings of the 15th International Conference on Environmental Science \& Technology 2017 (15th C.E.S.T. 2017), Rhodes Island, Greece, 31 August-2 September 2017; Lekkas, D.F., Ed.; cest2017_00842; Global Network for Environmental Science \& Technology (Global-NEST), University of the Aegean: Athens, Greece, 2017.

6. Monte Carlo Method. Available online: https://en.wikipedia.org/wiki/Monte_Carlo_method (accessed on 3 March 2018).

7. Koutsoyiannis, D. A Monte Carlo approach to water management (invited). In Proceedings of the European Geosciences Union General Assembly, Vienna, Austria, 22-27 April 2012; Geophysical Research Abstracts: Vienna Austria, 2012; Volume 14, 3509, pp. 1-45.

8. Flores, G. A Stochastic Model for Sewer Base Flows Using Monte Carlo Simulation. Master's Thesis, Stellenbosch University, Faculty of Engineering, Department of Civil Engineering, Stellenbosch, South Africa, March 2015.

9. Paisley, L.G.; Karlsen, E.; Jarp, J.; Mo, T.A. A Monte Carlo Simulation Model for Assessing the Risk of Introduction of Gyrodactylus Salaries to the Tana River, Norway. Dis. Aquat. Org. 1999, 37, 145-152. doi:10.3354/dao037145. Available online: http://www.int-res.com/abstracts/dao/v37/n2/p145-152/ (accessed on 3 March 2018).

10. Johnson, A. Modified Parshall Flume (U.S. Geological Survey Open-File Report), 1st ed.; United States Department of the Interior Geological Survey: Denver, CO, USA, 1963; pp. 1-8.

11. Rantz, S.E.; Barnes H.H.; Carter R.W.; Smoot G.F.; Matthai H.F.; Pendleton A.F.; Hulsing H.; Bodhaine G.L.; Davidian J.; Buchanan T.J.; et al. Measurement of Discharge by Miscellaneous Methods. In Measurement and Computation of Streamflow: Volume 1. Measurement of Stage and Discharge, 1st ed.; United States Government Printing Office: Washington, DC, USA, 1982; Volume 1, pp. 260-272.

12. Modified Parshall Flume-(U.S.G.S.). Available online: https://www.usgs.gov/media/images/modified-parshall-flume (accessed on 3 March 2018).

13. U.S.G.S. Portable Parshall Flume (Open-Channel-Flow Hydrological Equipment). Available online: https://www.openchannelflow.com/blog/usgs-portable-parshall-flume (accessed on 3 March 2018).

14. U.S.G.S. Portable Parshall Flume, 3in (Rickly Hydrological Equipment). Available online: http://rickly.com/usgs-portable-parshall-flume-3in/ (accessed on 3 March 2018).

15. Measuring Low Flow in San Pedro River. Available online: https://www.youtube.com/ watch?v=gLWtfMYicrI (accessed on 3 March 2018).

16. Inspecting a Parshall Flume (3-Inch USGS Modified Portable). Available online: https://www.youtube.com/watch?v=YtqflgfOb5E (accessed on 3 March 2018). 
17. Inspecting a Parshall Flume. Available online: https://www.youtube.com/watch?v=y6hiOLgTo6g (accessed on 3 March 2018).

18. Inspecting a Parshall Flume $(\mathrm{a}+\mathrm{b})$. Available online: https://www.youtube.com/watch?v=EgV5AKAYBe4 (accessed on 3 March 2018).

19. MSc. In Management of Water Resources in the Mediterranean 3. Available online: https://www.youtube.com/watch?v=picUMHITkx0 (accessed on 3 March 2018).

20. Father of the Flume: Ralph Parshall. Available online: https://lib2.colostate.edu/archives/water/parshall/ (accessed on 3 March 2018).

21. Papalaskaris, T.; Dimitriadou, P. Artificial Neural Network for Bed Load Transport Rate in Nestos River, Greece. Spec. Top. Rev. Porous Media 2017, 8, 145-157. doi:10.1615/SpecialTopicsRevPorousMedia. 2017019729. Available online: http://www.dl.begellhouse.com/journals/3d21681c18f5b5e7, 0e5e7d7c2836d626,2a6142094c2e98ac.html (accessed on 3 March 2018).

(C) 2018 by the authors. Licensee MDPI, Basel, Switzerland. This article is an open access article distributed under the terms and conditions of the Creative Commons Attribution (CC BY) license (http://creativecommons.org/licenses/by/4.0/). 